\title{
Low temperature vacuum sublimation refrigerators on carbon dioxide as working fluid Artem Frolovich Porutchikov ${ }^{(a)}$, Dmitriy Pavlovich Trubin ${ }^{(a)}$ \\ (a) Moscow Polytechnic University \\ Moskow, 107023, Russian Federation, porutchikov.artem@gmail.com
}

\begin{abstract}
The paper presents the results of theoretical and experimental analysis of a vacuumfreeze-drying refrigeration machine based on carbon dioxide. Such refrigeration machines can be equipped with refrigerators for the needs of medicine, where low temperatures are widely in demand in the range from minus 80 degrees Celsius to minus 130 degrees Celsius. The problem of developing alternative refrigeration machines is dictated by modern environmental requirements for working substances, which are gradually being tightened and soon the use of familiar freons will become impossible. For the air conditioning and commercial refrigeration industry, new substances are being actively developed, such as hydrofluoroolefins (HFOs), hydrocarbons can also serve as substitutes for hydrofluorocarbons and their mixtures, but it must be considered that they are combustible and explosive. A carbon dioxide vacuum sublimation unit may be an alternative to modern freon vapor compression refrigeration units for the indicated temperature range, but subject to comparable energy costs during its operation. The article examined the three-stage and four-stage cycles of a vacuum-freeze-drying refrigeration machine, conducted their theoretical comparison in terms of COP with a cascade cycle on hydrocarbon working substances. It can be noted that the COP of the considered cycles are close, but the environmental friendliness, safety and non-combustibility of carbon dioxide gives the advantages of a vacuum freeze-drying refrigeration machine.
\end{abstract}

Keywords: carbon dioxide, low pressure sublimation, refrigeration machine, low temperature medical freezers, refrigerants

\section{INTRODUCTION}

The problem of replacement of working substances of refrigerating machines (freons), which negatively affect the environmental situation in the world, is raised periodically. In the first half of the XX century chlorofluorocarbons were used, then chlorine was recognized as an ozone-depleting substance, they were gradually replaced by hydrochlorofluorocarbons, and then by hydrofluorocarbons. The next stage was the fight against the greenhouse effect, as a result of which new refrigerants - hydrofluorolefins and their mixtures with hydrofluorocarbons have been developed, which are already actively introduced in Europe and in the world, which is helped by legislative regulations on the withdrawal of old refrigerants from circulation [1-3]. Since the chemical production of developing countries do not 
always have time to adapt to the ever-increasing requirements of legislation regulating the turnover of refrigerants, the program of withdrawal from circulation of a number of refrigerants is designed to gradually reduce their consumption, including measures to replace working substances with transition mixtures [4], which avoids large one-time capital costs.

Currently, substances have already been developed that will soon replace the HFCs withdrawn from circulation, they will become hydrofluorolefins( HFO), they show themselves well when used as working bodies of heat pumps [5], when replacing R134a with R1234yf in ejector refrigerating machines [6]. It should be noted that the identified disadvantages of HFO are a possible decrease in the performance of the system [8], a large temperature glide, for CFC / HFC mixtures, which have a high non-azeotropy [9]. The second way of development, which allows to gradually withdraw from circulation substances with high indicators of global warming potential, is the use of natural working substances [7].

Currently developed HFO are mainly designed for commercial and industrial medium-temperature cooling, in the field of low temperatures, widely used in medicine where biomaterials are stored in individual low-temperature refrigerators, mixtures with HCFCs are still common. It is possible to solve the problem cardinally by using natural working substances, among which carbon dioxide stands out favorably, having a global warming coefficient (GWP) equal to one, $\mathrm{CO} 2$ is nontoxic, relatively inert, non-combustible, its use is not subject to additional regulation, the substance has a greater heat of the phase transition, which allows the use of compressors with lower volumetric capacity.

Carbon dioxide has already become quite firmly in use in low-temperature commercial and industrial refrigeration systems, which are built on the principle of cascade and transcritical [10-13], is used in heat pumps as a pure substance and in mixtures [14,15], acts as a cooling agent in low-temperature processing of metals [16-18], is used as a high-temperature coolant in gaseous form [20].

\section{THEORETICAL AND EXPERIMENTAL COMPARATIVES OF CYCLES}

To conduct a quantitative assessment of energy efficiency comparison, we compare the cycles of a steam compression cascade refrigeration machine on hydrocarbon working substances in two-stage and three-stage versions and a vacuum-sublimation refrigeration machine

\subsection{Schematic diagrams and thermodynamic cycles}

To calculate the cycles, take parameters that allow to compare systems in similar conditions: temperature of the phase transition in the heat exchanger load varies from minus 125 degrees $\mathrm{C}$ to minus $80^{\circ} \mathrm{C}$; condensing temperature $-30{ }^{\circ} \mathrm{C}$, pressure drop and loss in heat exchange apparatus for refrigerating machines is neglected, we believe that the compression processes take place without dissipation.

Designations of points of a thermodynamic cycle are accepted according to a technique, prof. I. M. Kalnina [21] where number of each point of a thermodynamic cycle has a designation from two digits "n. m", $n$ - level of pressure in a point, 
$\mathrm{m}$-process or a characteristic state in a point, the table of designations of processes and characteristic states is given below

For the phase transition temperatures of the working substance in the heat exchanger up to $-100{ }^{\circ} \mathrm{C}$ it is possible to use a two-stage refrigeration machine, as working substances we use propane in the upper stage and ethylene in the lower.

The vacuum-sublimation system is considered in two variants: with singlestage and two-stage vacuuming and compression, while the transition to two-stage compression at the lower stage is advisable to carry out at phase transition temperatures of minus $96{ }^{\circ} \mathrm{C}$ and below. Figure 1 shows the schematic diagrams of the systems under consideration.
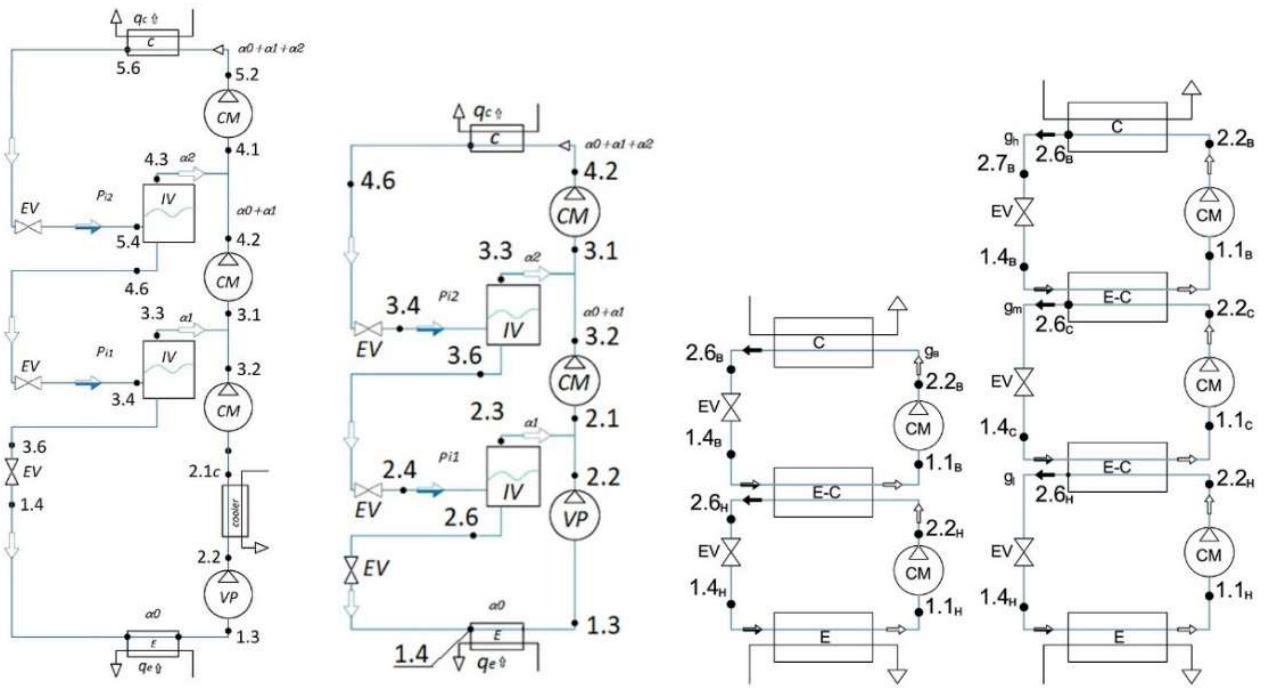

Figure 1. Schematic Diagrams of the systems under consideration

a) four-Stage HSCM with two compression stages at low pressure on carbon dioxide; b) three-Stage HSCM with one compression stage at low pressure on carbon dioxide; c) two-stage HSCM on hydrocarbons (R290; R1150); d) threeStage HSCM on hydrocarbons (R290; R170; R50)

\subsection{Calculation of the main parameters of cycles}

The specific work of compression in the cascade cycle is found by the expression (1), the number of terms, respectively, 2 and 3 for the two-stage and threestage cycle of PCM. 


$$
\mathrm{l}=\mathrm{l}_{1 \mathrm{st}}+\mathrm{l}_{2 \mathrm{st}}=\left(\mathrm{h}_{2.2}^{1 \text { cas }}-\mathrm{h}_{1.1}^{1 \mathrm{cas}}\right)+\alpha\left(\mathrm{h}_{2.2}^{2 \text { cas }}-\mathrm{h}_{1.1}^{2 \mathrm{cas}}\right)+\beta\left(\mathrm{h}_{2.2}^{3 \mathrm{cas}}-\mathrm{h}_{1.1}^{2 \mathrm{cas}}\right)\left[\frac{\mathrm{kJ}}{\mathrm{kg}}\right]
$$

where $\alpha$-is the relative mass flow rate of the working substance in the middle stage, and $\beta$ is in the upper stage, are from the expressions, equation (2)

$$
\alpha=\frac{q_{k}^{1 c a s}}{q_{0}^{2 c a s}} ; \quad \beta=\frac{q_{k}^{2 c a s}}{q_{0}^{3 c a s}}
$$

Specific cooling capacity in cascade cycle:

$$
q_{0}=q_{0}^{1 c a s}=\left(h_{1.3}^{1 c a s}-h_{1.4}^{1 c a s}\right)\left[\frac{\mathrm{kJ}}{\mathrm{kg}}\right]
$$

Compression operation in vacuum-sublimation refrigeration machine for singlestage and two-stage compression at low pressure, respectively:

$$
\left\{\begin{array}{c}
l_{\mathrm{BCXM}}=\left(h_{2.2}-h_{1.3}\right)+\left(1+\alpha_{1}\right)\left(h_{3.2}-h_{2.1}\right)+\left(1+\alpha_{1}+\alpha_{2}\right)\left(h_{4.2}-h_{3.1}\right)\left[\frac{\mathrm{kJ}}{\mathrm{kg}}\right] \\
l_{\mathrm{BCXM}}=\left(h_{2.2}-h_{1.3}\right)+\left(h_{3.2}-h_{2.1}\right)+\left(1+\alpha_{1}\right)\left(h_{4.2}-h_{3.1}\right)+ \\
\left(1+\alpha_{1}+\alpha_{2}\right)\left(h_{5.2}-h_{4.1}\right)\left[\frac{\mathrm{kJ}}{\mathrm{kg}}\right]
\end{array}\right.
$$

Eq. (4)

where: $\alpha_{1}$ - relative mass flow through the intermediate vessel PR1

$$
\alpha_{1}=\frac{\left(h_{3.4}-h_{3.6}\right)}{\left(h_{3.3}-h_{3.4}\right)}
$$

$\alpha_{2}$ - relative mass flow through the intermediate vessel PR2

$$
\alpha_{2}=\frac{\left(h_{4.4}-h_{4.6}\right)}{\left(h_{4.3}-h_{4.4}\right)}
$$

Specific cooling capacity in the cycle of vacuum-sublimation refrigeration machine

$$
q_{0}=\left(h_{1.3}-h_{1.4}\right)\left[\frac{\mathrm{kJ}}{\mathrm{kg}}\right]
$$

COP of the cycles

$$
\varepsilon=\frac{q_{0}}{l_{s}}
$$


The main factor affecting the final efficiency of the cycles, which is not always possible to calculate accurately, is the calculation of the compression process, which we carry out using isentropic efficiency, with the enthalpy of the point at the end of the compression process at each stage, we find by the expression (9).

$$
h_{* .2}=\frac{h_{* 2}^{S}-h_{* .1}}{\eta_{s}}+h_{* .1}\left[\frac{\kappa Д ж}{\kappa \Gamma}\right]
$$

where: $\eta_{s}-$ isentropic efficiency characterizing the compression process depends on the type of compression medium and the ratio of pressures at the beginning and end of the compression process, for a piston compressor is determined by empirical dependences like Figure. 2 .

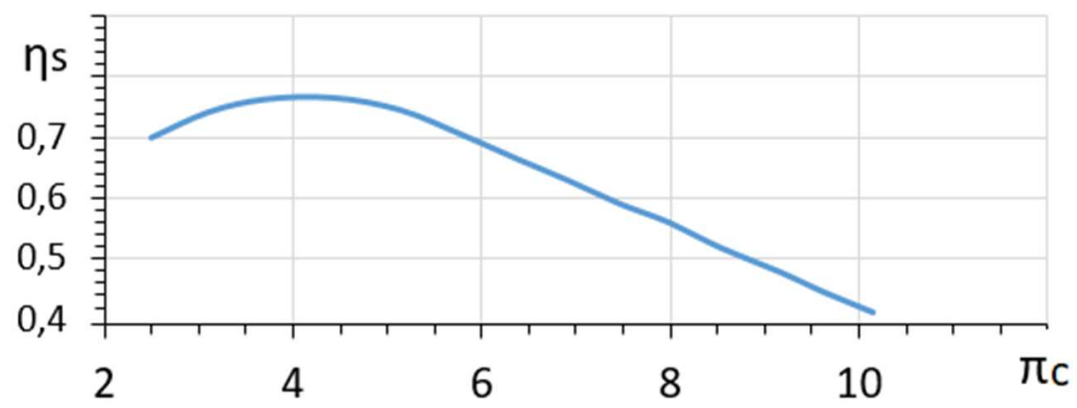

Figure 2. Graph for determining the value of the isotropic efficiency of the refrigerant compression process in a piston machine $[22,23]$

\subsection{Experimental determination of specific work of compression at work of the vacuum-sublimation refrigerating machine}

To carry out the experiments, was created installation Figure 3.

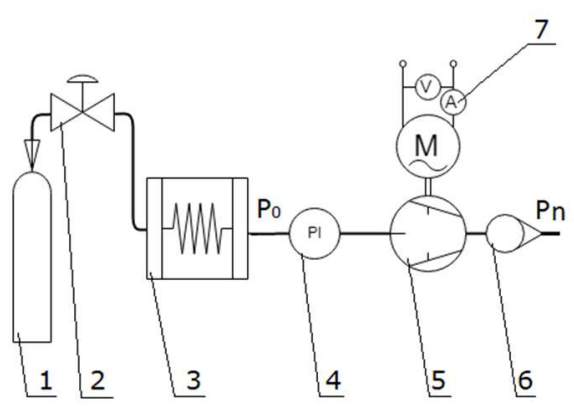

a)

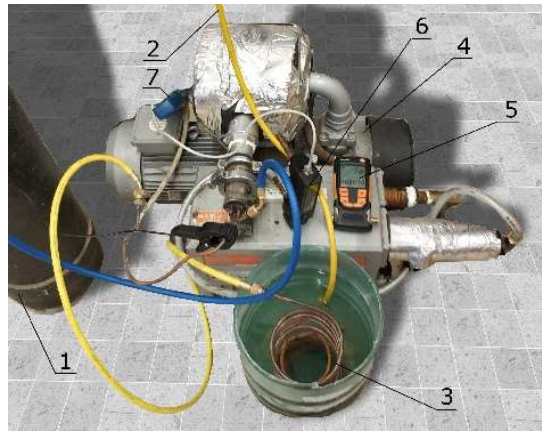

b)

Figure 3. Schematic diagram of the stand and appearance during the preparation of the experiment 
a). 1-high pressure liquid phase CO2 Cylinder; 2-pressure Reducer; 3-heat

Exchanger-heater for $\mathrm{CO} 2$ temperature stabilization; 4-electronic vacuum Meter; 5Vacuum plate-rotary pump with oil seal; 6-electronic Rotameter; 7-multi-Function multimeter for power measurement.

b) Stand appearance during commissioning

Installation allows to simulate the lower stage of vacuum-freeze refrigeration unit with single stage pumping to low pressure at the compression work in the cycle, as with single-stage and two-stage compression at low pressure respectively can be found from the expression (10)

$$
\left\{\begin{array}{c}
l=l_{\mathrm{ва \kappa}}^{\text {экп }}+\left(1+\alpha_{1}\right)\left(h_{3.2}-h_{2.1}\right)+\left(1+\alpha_{1}+\alpha_{2}\right)\left(h_{4.2}-h_{3.1}\right) \\
l=l_{\text {вак }}^{\text {экс }}+\left(h_{3.2}-h_{2.1}\right)+\left(1+\alpha_{1}\right)\left(h_{4.2}-h_{3.1}\right)+\left(1+\alpha_{1}+\alpha_{2}\right)\left(h_{5.2}-h_{5.1}\right)
\end{array}\right.
$$

During the experiment, carbon dioxide in the form of steam is supplied from a high-pressure cylinder. where is liquid in the reducer, where its pressure is reduced to the suction pressure of the vacuum pumping means is then supplied to the heater, where its temperature rises to the functioning temperature measuring devices, then pair the carbon dioxide pass through the flow vacuumed and drawn into the vacuum pump where it is compressed to atmospheric pressure and directed to a mass flowmeter, then released into the atmosphere.

Thus we are able to measure the mass flow of carbon dioxide, the power consumed by the motor of the vacuum pump, the pressure level at the inlet to the vacuum pump, and since it depends only on the pressures at the inlet and outlet and flow rate of the substance and the type of pump, according to the findings we can draw conclusions about the energy consumption of the vacuum pump as a vacuumfreeze refrigeration unit, the temperature of sublimation is determined by the parameters of saturation on the line solid-vapor NIST [24].

To calculate the power consumed by the electric motor of the vacuum pump, the voltage and current at one of the phases of the electric motor was measured using the universal multifunctional current and voltage meter, the power consumed by the electric motor from the network can be found according to the expression (11).

$$
P=3 \times U_{R M S} \times I_{R M S} \times \cos (\varphi)[W]
$$

where: $U_{R M S}, I_{R M S}-$ RMS values of current and voltage measured on the stand during pump operation;

$\cos (\varphi)$ - cosine of the angle between the vector current and voltage;

Тогда удельная работа сжатия насоса может быть вычислена по выражению (12).

$$
l_{\mathrm{BaK}}^{S}=\frac{P}{G_{\mathrm{CO}_{2}}}\left[\frac{\mathrm{kJ}}{\mathrm{kg}}\right]
$$


where: $G_{\mathrm{CO}_{2}}$ - mass flow rate of carbon dioxide pumped by the pump, measured using an electronic rotameter.

Table 1 presents the calculated data and the data obtained from the experiments on the stand (marked with an asterisk).

\begin{tabular}{|c|c|c|c|c|c|c|c|c|c|c|c|}
\hline $\mathrm{p}_{0} *$ & $\mathrm{t}_{0}$ & $\mathrm{P} *$ & $\mathrm{G}^{*}$ & $\mathrm{q}_{0}$ & $1_{1 \mathrm{st}} *$ & $1_{1 \text { st }}$ & $1_{2 s t}$ & $1_{3 s t}$ & $1_{4 s t}$ & $\sum 1$ & $\varepsilon$ \\
\hline 0,6 & $-125,51$ & 2,10 & $1,5 \times 10^{-5}$ & $\begin{array}{c}310 \\
2\end{array}$ & 139048,6 & 471,2 & 158,9 & $\begin{array}{c}196 \\
4\end{array}$ & 448 & 140516,2 & 0,002 \\
\hline 0,8 & $-123,52$ & 2,10 & $5,4 \times 10^{-5}$ & $\begin{array}{c}310 \\
2\end{array}$ & 39728,2 & 433,6 & 158,9 & $\begin{array}{c}196 \\
4\end{array}$ & 448 & 41195,8 & 0,008 \\
\hline 1,0 & $-121,93$ & 2,10 & $1,3 \times 10^{-4}$ & $\begin{array}{c}310 \\
2\end{array}$ & 16358,7 & 405,6 & 158,9 & $\begin{array}{c}196 \\
4\end{array}$ & 448 & 17826,3 & 0,017 \\
\hline 1,1 & $-121,24$ & 2,10 & $1,61 \times 10^{-4}$ & $\begin{array}{c}310 \\
2\end{array}$ & 13254,9 & 393,9 & 158,9 & $\begin{array}{c}196 \\
4\end{array}$ & 448 & 14722,6 & 0,021 \\
\hline 1,2 & $-120,6$ & 2,10 & $1,78 \times 10^{-4}$ & $\begin{array}{c}310 \\
2\end{array}$ & 11972,2 & 383,4 & 158,9 & $\begin{array}{c}196, \\
4\end{array}$ & 448 & 13439,8 & 0,023 \\
\hline 1,3 & $-120,01$ & 2,10 & $1,93 \times 10^{-4}$ & $\begin{array}{c}310 \\
2 \\
\end{array}$ & 11029,0 & 373,8 & 158,9 & $\begin{array}{c}196, \\
4 \\
\end{array}$ & 448 & 12496,6 & 0,025 \\
\hline 1,4 & $-119,46$ & 2,10 & $2,26 \times 10^{-4}$ & $\begin{array}{c}310 \\
2\end{array}$ & 9448,8 & 365,1 & 158,9 & $\begin{array}{c}196 \\
4\end{array}$ & 448 & 10916,4 & 0,028 \\
\hline 1,5 & $-118,95$ & 2,10 & $2,77 \times 10^{-4}$ & $\begin{array}{c}310 \\
2\end{array}$ & 7696,5 & 357 & 158,9 & $\begin{array}{c}196 \\
4\end{array}$ & 448 & 9164,1 & 0,034 \\
\hline 1,7 & -118 & 2,30 & $7,98 \times 10^{-4}$ & $\begin{array}{c}310 \\
2\end{array}$ & 2882,4 & 342,7 & 158,9 & $\begin{array}{c}196 \\
4\end{array}$ & 448 & 4350 & 0,071 \\
\hline 2,3 & $-115,66$ & 2,40 & $1,23 \times 10^{-3}$ & $\begin{array}{c}310 \\
2\end{array}$ & 1917,8 & 309,1 & 158,9 & $\begin{array}{c}196, \\
4\end{array}$ & 448 & 3385,5 & 0,092 \\
\hline 3,2 & $-113,02$ & 2,40 & $2,53 \times 10^{-3}$ & $\begin{array}{c}310 \\
2 \\
\end{array}$ & 931,3 & 274,2 & 158,9 & $\begin{array}{c}196 \\
4 \\
\end{array}$ & 448 & 2398,9 & 0,129 \\
\hline 6,0 & $-107,71$ & 2,00 & $2,75 \times 10^{-3}$ & $\begin{array}{c}310 \\
2\end{array}$ & 734,9 & 212,5 & 158,9 & $\begin{array}{c}196, \\
4\end{array}$ & 448 & 2202,5 & 0,141 \\
\hline 6,8 & $-106,61$ & 2,00 & $2,88 \times 10^{-3}$ & $\begin{array}{c}309 \\
2\end{array}$ & 702,2 & 200,9 & 158,9 & $\begin{array}{c}196 \\
4\end{array}$ & 448 & 2169,9 & 0,142 \\
\hline 10,4 & $-102,75$ & 2,00 & $5,78 \times 10^{-3}$ & $\begin{array}{c}307 \\
2\end{array}$ & 349,1 & 169,7 & 158,9 & $\begin{array}{c}196 \\
4\end{array}$ & 448 & 1816,8 & 0,169 \\
\hline 15,0 & $-99,269$ & 2,00 & $9,4 \times 10^{-3}$ & $\begin{array}{c}306 \\
2\end{array}$ & 214,9 & 149,4 & 158,9 & $\begin{array}{c}196 \\
4\end{array}$ & 448 & 1682,5 & 0,182 \\
\hline 19,1 & $-96,89$ & 2,00 & $1,19 \times 10^{-2}$ & $\begin{array}{c}305 \\
2\end{array}$ & 170,3 & 150,9 & 158,9 & $\begin{array}{c}196, \\
4 \\
\end{array}$ & 448 & 1637,9 & 0,186 \\
\hline 30,1 & $-92,225$ & 2,10 & $1,94 \times 10^{-2}$ & $\begin{array}{c}303 \\
2\end{array}$ & 107,1 & 238,6 & - & $\begin{array}{c}219, \\
6 \\
\end{array}$ & $\begin{array}{c}514, \\
9\end{array}$ & 1603,5 & 0,189 \\
\hline 36,5 & $-90,171$ & 2,10 & $2,328 \times 10^{-2}$ & $\begin{array}{c}302 \\
2 \\
\end{array}$ & 89,2 & 219,3 & - & $\begin{array}{c}211, \\
7 \\
\end{array}$ & 499 & 1538 & 0,196 \\
\hline
\end{tabular}




\begin{tabular}{|c|c|c|c|c|c|c|c|c|c|c|c|}
\hline 41,8 & $-88,697$ & 2,10 & $2,473 \times 10^{-2}$ & $\begin{array}{c}300, \\
2\end{array}$ & 83,9 & 206,1 & - & $\begin{array}{c}206, \\
2\end{array}$ & 488 & 1499,7 & 0,200 \\
\hline 45,3 & $-87,812$ & 2,10 & $2,878 \times 10^{-2}$ & $\begin{array}{c}299, \\
2\end{array}$ & 74,1 & 198,3 & - & 203 & $\begin{array}{c}481, \\
5\end{array}$ & 1470,5 & 0,203 \\
\hline 50,0 & $-86,814$ & 2,10 & $3,196 \times 10^{-2}$ & $\begin{array}{c}298, \\
2\end{array}$ & 66,7 & 188,9 & - & 199 & $\begin{array}{c}473, \\
4\end{array}$ & 1438,9 & 0,207 \\
\hline 55,7 & $-85,498$ & 2,10 & $3,572 \times 10^{-2}$ & $\begin{array}{c}297, \\
2\end{array}$ & 59,7 & 178,9 & - & 194, & 464, & 1406,4 & 0,211 \\
9 & & & & & & & \\
\hline
\end{tabular}

Table 1. Calculated and experimental data

Table 2 presents the calculated data on the COP depending on the boiling point for two-stage and three-stage refrigeration machines on hydrocarbons.

\begin{tabular}{|l|l|l|l|l|l|l|l|l|l|l|}
\hline & \multicolumn{9}{|c|}{ Twocascade VCRS R290, R1150 } & \multicolumn{6}{l|}{ Threecacsade VCRS R290, R170, } \\
R50 \\
\hline $\mathrm{t}_{0},{ }^{\circ} \mathrm{C}$ & -80 & -85 & -90 & -95 & -100 & -105 & -110 & -115 & -120 & -125 \\
\hline$\varepsilon$ & 0,65 & 0,527 & 0,405 & 0,283 & 0,324 & 0,24 & 0,233 & 0,224 & 0,212 & 0,194 \\
\hline
\end{tabular}

Table 2. Data Obtained By Calculation For The Cop Of Cascade Refrigerating Machines On Hydrocarbons

\section{SUMMARY}

According to the obtained data, it is possible to construct a comparative graph of COP at different phase transition temperatures at the lower temperature levels of cascade VCRS and vacuum-sublimation refrigerating machines Figure 4. 


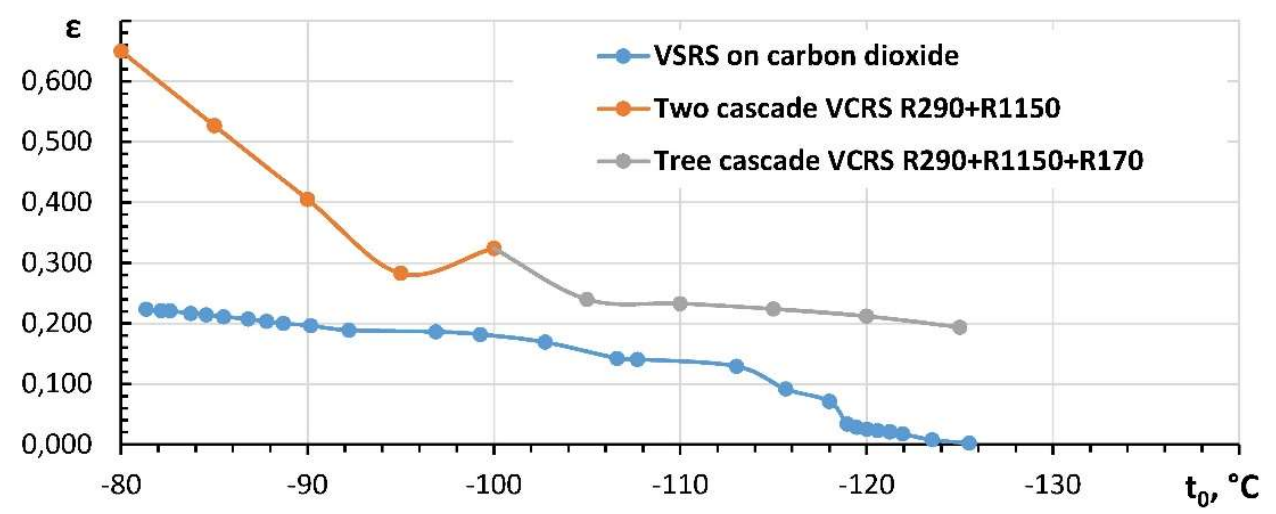

Figure 4. Dependence of the COP on the temperature of the phase transition in cascade PCCM and vacuum-sublimation on carbon dioxide

As shown by experiments at temperatures below $-115^{\circ} \mathrm{C}$, the COP of the vacuum-freeze refrigeration unit drops significantly due to the sharp growth of specific work of compression of the vapour of carbon dioxide, this can be explained by high unit costs rotary vane vacuum pump used in the experimental stand, as can be seen from the data in table 1, the power consumed by the pump motor is almost independent of the suction pressure with low pressure sublimation vapor density falls, as a result, the mass flow rate of the working substance will decrease and the total cooling capacity of the system will fall, the use of dry means of vacuum pumping for use in the first stage of the VSRS is seen as promising.

In the course of calculations and experiments, cascade cycles of VCRS showed higher COP capacity in the entire temperature range, but in the range from minus $95{ }^{\circ} \mathrm{C}$ to minus $115{ }^{\circ} \mathrm{C}$, the difference in COP is about $40 \%$, which is significant, but given the not optimal choice of a vacuum pump for experimental studies, it can be concluded that the vacuum-sublimation method of obtaining low temperatures can be compared in efficiency with cascade VCRS. The advantages of carbon dioxide remain, its environmental friendliness and complete safety.

NOMENCLATURE

\begin{tabular}{|l|l|l|l|}
\hline$p_{0}$ & evaporating pressure $(\mathrm{kPa})$ & $*$ & $\begin{array}{l}\text { experimental data from the } \\
\text { installation }\end{array}$ \\
\hline$t_{0}$ & evaporating temperature $\left({ }^{\circ} \mathrm{C}\right)$ & $l, m, h$ & $\begin{array}{l}\text { low, middle, high cascade } \\
\text { indexes }\end{array}$ \\
\hline$P$ & power $(\mathrm{kW})$ & $V C R S$ & $\begin{array}{l}\text { vapor compression refrigeration } \\
\text { machine }\end{array}$ \\
\hline$g$ & mass flow rate $(\mathrm{kg} / \mathrm{s})$ & $V S R S$ & $\begin{array}{l}\text { vacuum sublimation } \\
\text { refrigeration machine }\end{array}$ \\
\hline$q_{0}$ & $\begin{array}{l}\text { specific cooling capacity } \\
(\mathrm{kJ} / \mathrm{kg})\end{array}$ & $C M$ & compressor \\
\hline
\end{tabular}




\begin{tabular}{|l|l|l|l|}
\hline$l$ & $\begin{array}{l}\text { specific compression work } \\
(\mathrm{kJ} / \mathrm{kg})\end{array}$ & $E V$ & expansion valve \\
\hline$\varepsilon$ & COP & $I V$ & intermediate vessel \\
\hline$\eta_{\mathrm{s}}$ & isoentropic efficiency & $V P$ & vacuum pump \\
\hline$\pi_{\mathrm{c}}$ & compression ratio & $C$ & condenser \\
\hline $\mathrm{P}_{\mathrm{n}}$ & normal pressure & $E$ & evaporator \\
\hline$l_{s t}$ & number of compression stage & $C-E$ & condenser - evaporator \\
\hline
\end{tabular}

\section{REFERENCES}

1. G.F. Hundy, (2016). Refrigeration, air conditioning and heat pumps. Butterworth-Heinemann.

2. O.B. Tsvetkov \& Y.A. Laptev (2017, November). Refrigerants and environment. In Journal of Physics Conference Series (Vol. 891, No. 1).

3. Regulation (EU) No 517/2014 of the European Parliament and of the Council of 16 April 2014 on fluorinated greenhouse gases and repealing Regulation (EC) No 842/2006 Text with EEA relevance

4. Mota-Babiloni, A., Navarro-Esbrí, J., Barragán-Cervera, Á., Molés, F., \& Peris, B. (2015). Analysis based on EU Regulation No 517/2014 of new $\mathrm{HFC} / \mathrm{HFO}$ mixtures as alternatives of high GWP refrigerants in refrigeration and HVAC systems. International journal of refrigeration, 52, 21-31.

5. G.A. Longo, C. Zilio, G. Righetti, \& J. S. Brown, (2014). Experimental assessment of the low GWP refrigerant HFO-1234ze (Z) for high temperature heat pumps. Experimental Thermal and Fluid Science, 57, 293-300.

6. Y.Fang, S. Croquer, S. Poncet, Z. Aidoun \& Y. Bartosiewicz, (2017). Drop-in replacement in a R134 ejector refrigeration cycle by HFO refrigerants. international journal of refrigeration, 77, 87-98.

7. K. Nawaz, \& M.R. Ally, (2019). Options for low-global-warming-potential and natural refrigerants Part 2: Performance of refrigerants and systemic irreversibilities. International Journal of Refrigeration.

8. Y. Fang, S. Croquer, S. Poncet, Z. Aidoun, , \& Y. Bartosiewicz, (2017). Dropin replacement in a R134 ejector refrigeration cycle by HFO refrigerants. international journal of refrigeration, 77, 87-98.

9. A. Şencan, İ. İ. Köse, \& R. Selbaş, (2011). Prediction of thermophysical properties of mixed refrigerants using artificial neural network. Energy conversion and management, 52(2), 958-974.

10. E. Gholamian, P. Hanafizadeh, \& P. Ahmadi, (2018). Advanced exergy analysis of a carbon dioxide ammonia cascade refrigeration system. Applied Thermal Engineering, 137, 689-699.

11. S.H. Mohammadi, (2018). Theoretical investigation on performance improvement of a low-temperature transcritical carbon dioxide compression refrigeration system by means of an absorption chiller after-cooler. Applied Thermal Engineering, 138, 264-279.

12. Y. Ma, Z. Liu, \& H. Tian (2013). A review of transcritical carbon dioxide heat pump and refrigeration cycles. Energy, 55, 156-172. 
13. G. P. Montagner \& C. Melo, (2014). A study on carbon dioxide cycle architectures for light-commercial refrigeration systems. International journal of refrigeration, 42, 90-96.

14. L.H.P. Massuchetto, , R. B. C. do Nascimento, S. M. R. de Carvalho, H. V.de Araújo, , \& d'Angelo, J. V. H. (2019). Thermodynamic performance evaluation of a cascade refrigeration system with mixed refrigerants: R744/R1270, R744/R717 and R744/RE170. International Journal of Refrigeration, 106, 201-212.

15. I.H. Bell, P.A. Domanski, M.O. McLinden, , \& G.T. Linteris, (2019). The hunt for nonflammable refrigerant blends to replace R-134a. International Journal of Refrigeration.

16. M.I. Sadik, S. Isakson, A. Malakizadi \& L. Nyborg, (2016). Influence of coolant flow rate on tool life and wear development in cryogenic and wet milling of Ti-6Al-4V. Procedia CIRP, 46, 91-94.

17. F. Pušavec, D. Grguraš, , M. Koch, , \& P. Krajnik, (2019). Cooling capability of liquid nitrogen and carbon dioxide in cryogenic milling. CIRP Annals..

18. B.D. Jerold, , \& M.P. Kumar, (2012). Experimental comparison of carbondioxide and liquid nitrogen cryogenic coolants in turning of AISI 1045 steel. Cryogenics, 52(10), 569-574.

19. M.A. Prelas, N.E. White, D.A. Wisniewski, K.L.Walton, M.T. Tchouaso, , Boraas, M.A., ... \& Watermann, M. L. (2018). Thermal to optical energy conversion: A multi megawatt carbon dioxide laser driven by an extremely high temperature gas cooled reactor. Progress in Nuclear Energy, 107, 155171 .

20. G. Garrett, \& \& J. Watson, (2019). Comparison of water, helium, and carbon dioxide as coolants for next generation power plants using TRACE. Annals of Nuclear Energy, 126, 292-302.

21. I.M. Kalnin \& K.N. Fadekov (2006). Thermodynamic cycles of refrigeration machines and heat pumps.

22. A.V. Bykov, E.M. Bezhanishvili, I.M. Kalnin (1992). Refrigeration Compressors / Ed. A.V. Bykov

23. E.W. Lemmon, M. L. Huber, , \& M.O. McLinden (2010). NIST Standard Reference Database 23, Reference Fluid Thermodynamic and Transport Properties (REFPROP), version 9.0, National Institute of Standards and Technology. R1234yf. fld file dated December, 22, 2010.

24. O. Podtcherniaev, M. Boiarski, , \& A. Lunin, (2002). Comparative performance of two-stage cascade and mixed refrigerant systems in a temperature range from-100C to-70C. 